\title{
THE INFLUENCE OF TECHNOLOGICAL PARAMETERS AS THE HANDLING AND SINTERING PROCESS ON THE STRUCTURE OF IRON BASED POWDERS
}

\author{
${ }^{1}$ Agnieszka STANULA, ${ }^{1}$ Wirginia PILARCZYK, ${ }^{2}$ Mark JAGER, ${ }^{1}$ Tomasz WILK \\ ${ }^{1}$ Silesian University of Technology, Faculty of Mechanical Engineering, Gliwice, Poland, EU, \\ Agnieszka.Stanula@polsl.pl,.Wirginia.Pilarczyk@polsl.pl \\ ${ }^{2}$ Monroe Country Community College, Faculty of Materials Technology, Monroe, Michigan, USA, \\ mjager@monroeccc.edu
}

https://doi.org/10.37904/metal.2020.3626

\begin{abstract}
The subject of this article is the failed bushing used in the car suspension. The claim of the broken bushing came from the car producer. The main aim of this paper was to know if the failure was a green crack as evidenced by steam treatment oxide on the crack interfaces. To check, these items a Scanning Electron Microscope (SEM), hardness testers, and optical microscope were used. The density of the upper edge where the crack occurred was checked. Based on this investigation it was found that the crack was not caused by the rollover application.
\end{abstract}

Keywords: Density, crack, sintering, compacting

\section{INTRODUCTION}

The concept of this paper is the failed part, made of FC0208-40 material [1]. The research is to check a green crack as evidenced by steam treatment oxide on the crack interfaces and the metallurgical integrity of the sample.

Technologies that are characterized by the processes of shaping workpieces, in which the fluidity of materials with complex rheology is implemented under conditions of complex loading, need new developments, learning, and improvement [2].

The presence of and/or the potential for cracking in powder metallurgy components is an industry recognized quality concern. In an industry wide survey, the elimination or controlling of cracks was identified as the second most important research priority. The general improvement of the mechanical properties was identified as the number one issue. It should be noted, however, that the benefits of the material properties only slightly exceeded that of the cracking issue in importance to the industry respondents of the respondents.

Cracks in Powder Material components primarily originate in consolidation or handling prior to the sintering process. Although a crack may not become evident until sintering has occurred, the root cause is most likely poor interparticle bonding prior to the sintering phase. The research has focused on cracks initiated prior to sintering [3]

The main causes of cracks found in the study can be summarized into four basic categories: improper material composition, interparticle side shifting action, improper elastic strain release and high tensile / shear stresses [4].

Sintered ferrous components can, in principle, be heat-treated like conventional steel parts. Thus, ferrous sintered parts can be through-hardened, case-hardened, and precipitation-hardened, However, due to its porosity and, in some cases, its heterogeneous alloy composition, sintered ferrous material in certain respects, will respond somewhat differently to heat-treatment than conventional steels [5]. 
Sintered steels are widely used for the manufacturing of automobile structural parts such as synchronizer gears, timing sprockets, transmission clutch plates and rollers, power steering pressure plates, etc. Porosity complicates machining of these steels by virtue of the non-availability of a smooth and continuous metal matrix for cutting. This leads the tool to experience non-continuous cutting, micro-vibrations, fatigue loading, and a chipping prone environment [6].

\section{MATERIALS AND EXPERIMENTS}

The publication presents overall photographs including the uneven rollover, visual analysis, SEM fractography surface finish of the bushing, density metallography and, combined carbon content. The tested material is FC0208-40 with a surface finish. This material consists of iron, copper (1.5-3.9 wt\%) and, carbon (0.6-0.9 wt\%). A visual check was carried out using the SEM microscope, and hardness, and density measurements were made according to MPIF 42 [7].

For density check: an analytical balance, a container with water, and a vacuum system were used. Method uses Archimedes principle - weight the specimen in air and in water. The Rockwell Superficial 3JS was used for checking hardness. The samples were prepared for metallurgical evaluation as follow: $2 \%$ Nital etching, epoxy resins mounting, grinding, and polishing.

\section{RESULTS}

Based on the results the following conclusions were made: The part appears to have been made with a lowdensity area at the upper edge as illustrated by the analysis. The low-density area appears to have separated in the green state of the bushing to a depth of $250 \mu \mathrm{m}-700 \mu \mathrm{m}$ from the outer diameter to the inner diameter. It is believed that the crack was opened further during the rollover operation, which would explain why there was evidence of a green crack that changed to cracking of sintered particles as the crack progressed to the inner diameter.

A density requirement was not on the finished part blueprint, so it is not known if the overall part density was satisfactory. However, it may be advisable to place a sectional density requirement on the upper edge to prevent this type of failure in the future.

\subsection{Visual Analysis}

The part was photographed as received to document its condition and the photographs are found below in (Figure 1) and in (Figure 2). Initial observations of the bushing/rollover assembly found a crack around the circumference of the upper edge approximately $50 \mathrm{~mm}$ long (Figure 1).

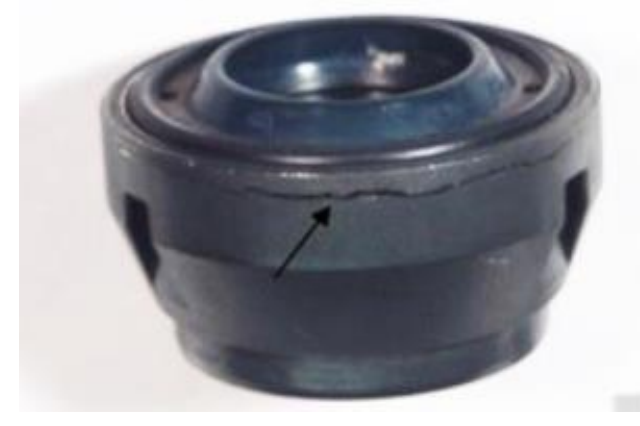

Figure 1 Bushing assembly as received. Crack is visible just below upper edge of the bushing

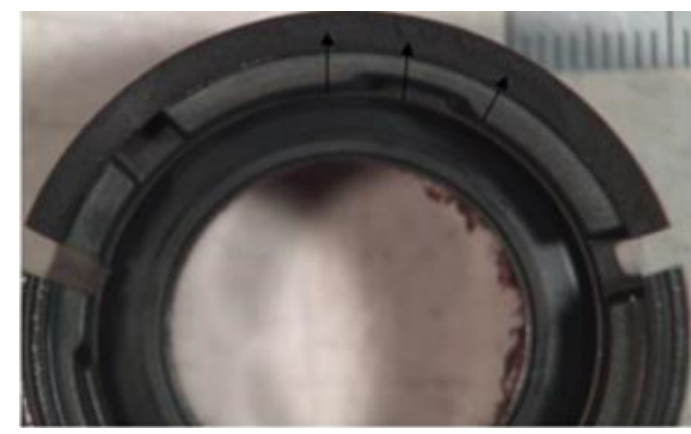

Figure 2 Overview of fracture face after removal of the upper edge. The fracture was found to change appearance toward the outside edge. The image above shows this change at the arrows 
After the initial observations were made, the upper edge was removed from the part for examination in the Scanning Electron Microscope (SEM). Once removed, the area underneath the broken portion exhibited steam treatment across the fracture face, with a change in appearance toward the outer edges (Figure 2).

Of note, the presence of steam treatment on the fracture face does not automatically indicate a green crack, as the steam treatment penetrates through the entire part via interconnected porosity. (Figure 3a) below, illustrates this as the bushing was split in half to show the darkened appearance to the fracture face vs. the appearance of the part due to abrasive saw cutting (silver) (Figure 3b).

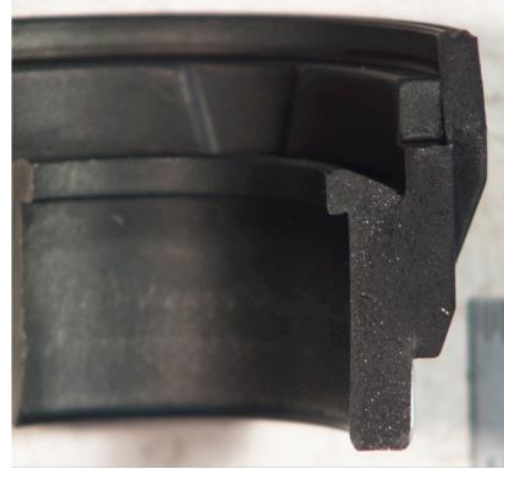

Figure 3a Laboratory created fracture

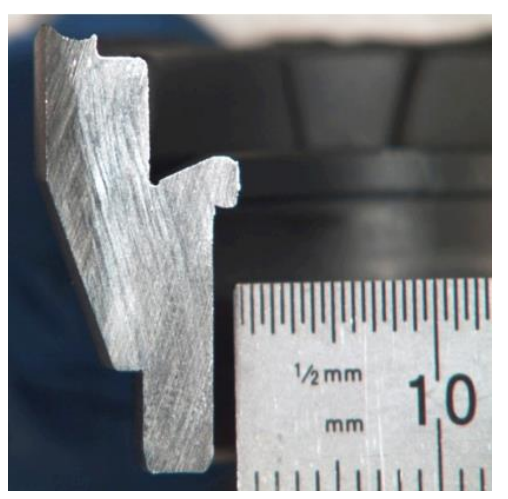

Figure $\mathbf{3 b}$ Abrasive saw cut surface

Notice the change in appearance based on the method of separation.

Examination of the fracture in the SEM found a band of what appeared to be a green crack extending from the outer diameter of the bushing to between 250-700 $\mu \mathrm{m}$ deep in the area detailed (Figure 3a) and (Figure 3b).

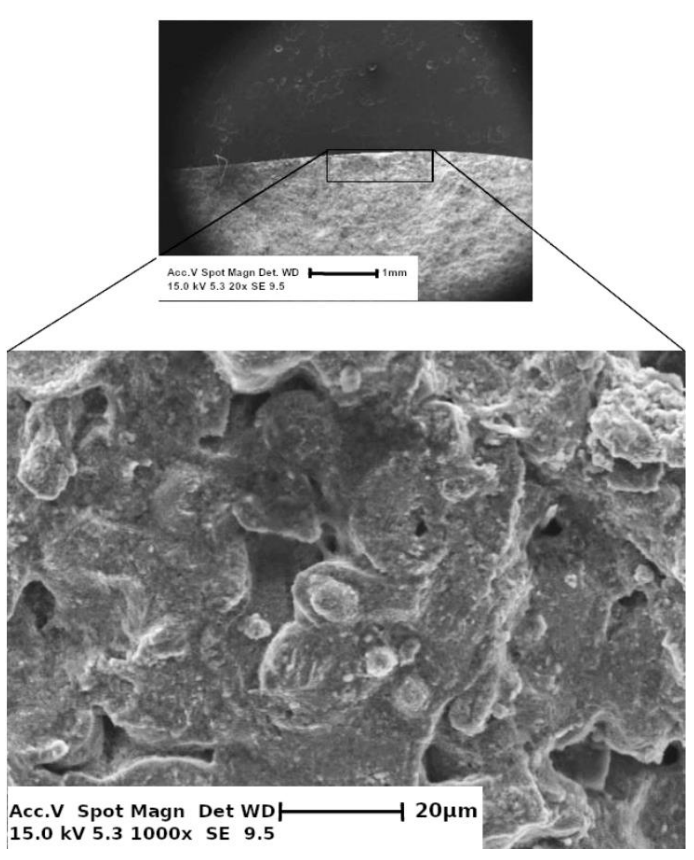

Figure 4 SEM image of the surface at the outer diameter of the fracture. Notice the lack of a fracture mode with an uninterrupted steam treat layer

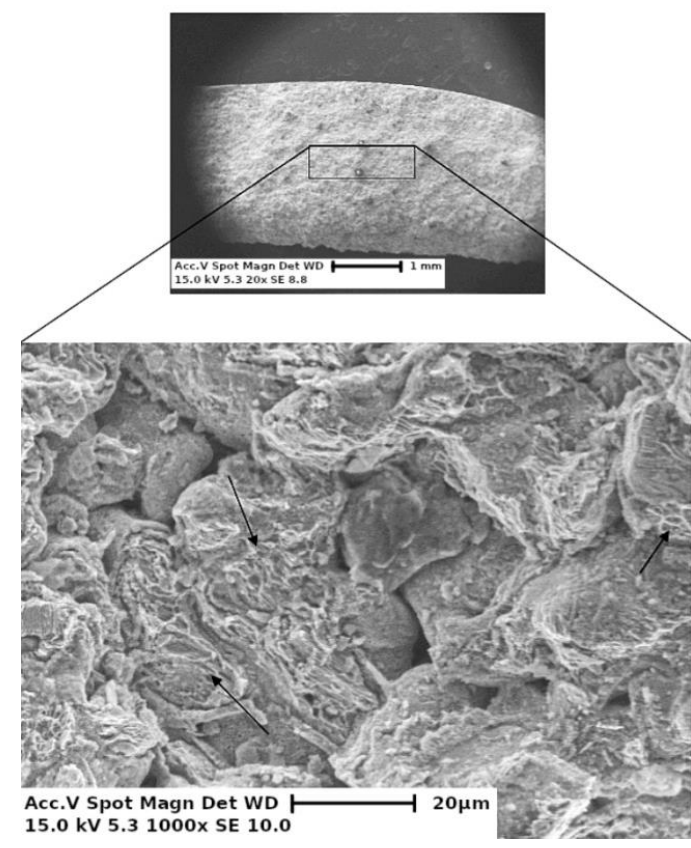

Figure 5 SEM image of the fracture face near the center of the fracture. Individual particles were found with dimple ruptures on the fracture faces (arrows). This indicates these particles and this area were fused together during sintering 
The surface appears to be an uninterrupted steam treatment layer, with individual powder particles visible (Figure 4).

For comparison, the fracture face immediately inboard was found to exhibit a completely different appearance (Figure 5). The presence of the material fracture was found on the powder metal particles in the form of a dimple rupture, indicating this area was fused during sintering.

\subsection{Hardness}

The bushing hardness was measured in two places. While hardness readings could be obtained, it should be noted that ASTM E18 [8] requires the hardness indentation to be as per the following:

- $\quad$ The distance between the centers of two adjacent indentations shall be at least three times the diameter of the indentation.

- The distance from the center of any indentation to the edge of the test piece shall be at least two and a half times the diameter of the indentation.

In order to obtain hardness values on this sample, requirement \#2 had to be violated. As such, the numbers below should be viewed for informational purposes only. Material yielding was also noticed on the check valve portion of the bushing (Area A). This is presented in Figure 6 The hardness results are given in Table 1.

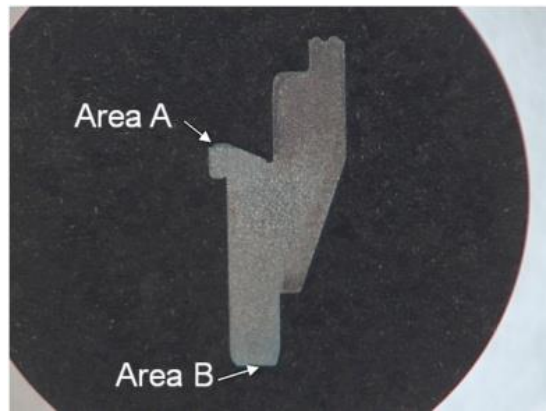

Figure 6 Areas of hardness readings

Table 1 Hardness Readings FC0208-40 material

\begin{tabular}{|c|c|c|c|c|c|}
\hline Area & \multicolumn{5}{|c|}{ Hardness (HRBW) } \\
\hline A & 90.5 & 91.0 & 90.0 & 88.0 & 89.0 \\
\hline B & 96.0 & 95.5 & 96.5 & 96.0 & 96.0 \\
\hline
\end{tabular}

\subsection{Density}

The density of the bushing is stated below: Section A - $6.38 \mathrm{~g} / \mathrm{cm}^{3}$ as steamed. Section B $-6.48 \mathrm{~g} / \mathrm{cm}^{3}$ as steamed.

\subsection{Metallography}

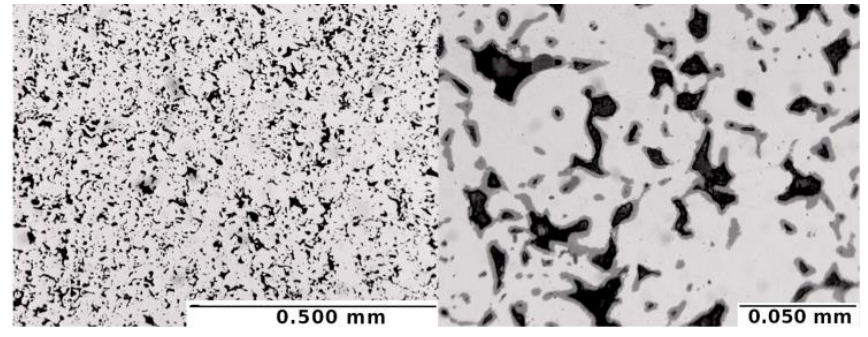

Figure 7 Unetched microstructure of the body of the bushing. Powder particles appear to have a satisfactory compaction and distribution

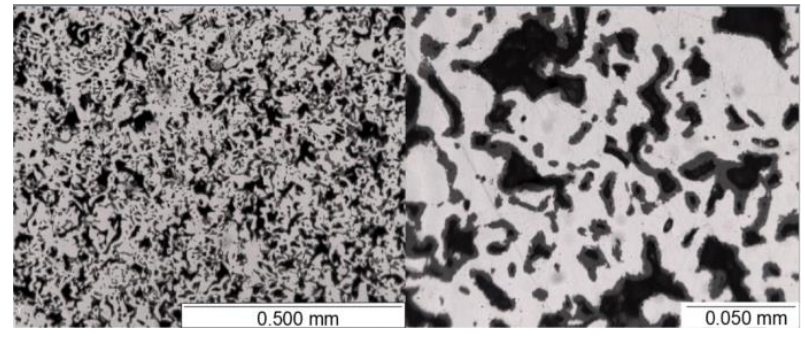

Figure 8 Unetched microstructure of the upper edge of the bushing. Powder particles appear to be loosely packed, with small sinter necks between the particles. This area would most likely have a lower density than the full panel, which would make this a lower strength area 
A section from the part was removed directly behind the fractured area and prepared as per ASTM E3 for microstructural evaluation. A marked difference in density was found between the body, and the upper edge of the part (Figure 7). It appears that the fractured area may not have had a proper fill or compaction (Figure 8).

For comparison, the etched structure of the upper edge reveals a much less dense particle network (Figure 9) and (Figure 10).

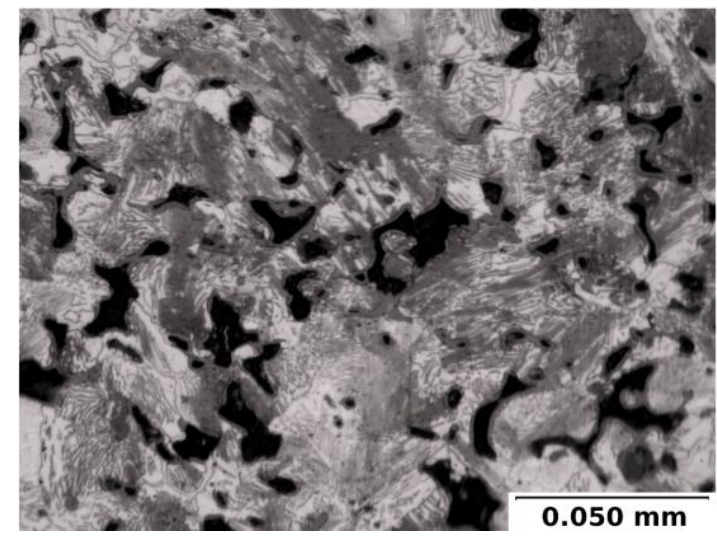

Figure 9 Etched microstructure in the body of the bushing. Combined carbon by way of visual estimate was $0.6 \%$. The part was specified to be FC0208-40 material and this level of carbon retention would be satisfactory

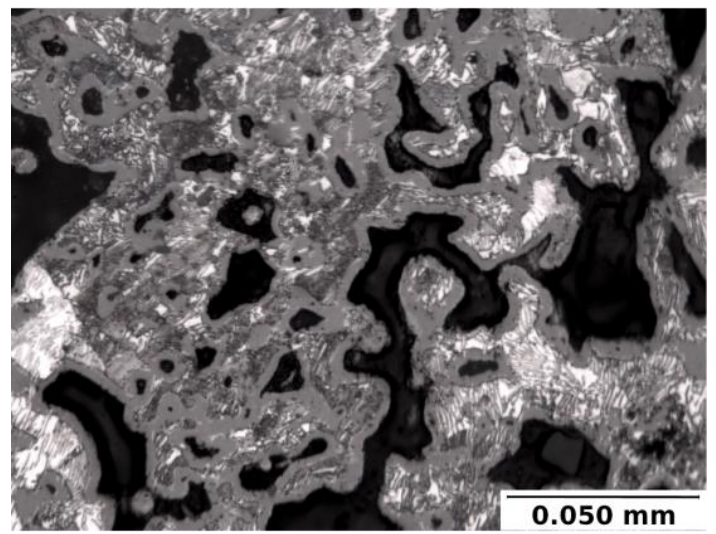

Figure 10 Etched microstructure of the upper edge of the bushing showing a low-density particle network

\section{CONCLUSIONS}

The mechanical properties of fully dense metallic materials are defined by the structural state, and by the surface microgeometry. The design choices are made based on the knowledge of these parameters [9]. The SEM analysis, metallography check, hardness and density show the presumed rules. The equipment and methods were a key for the material structure investigation.

In conclusion, the reason for the broken bushing was found. The improper handling of the details during interoperative transport caused mechanical damage to a single piece before the sintering operation. The factor conducive to mechanical damage is that the density on the upper part is not very high (but still according to tolerance). The defect is not visible at the production stage.

\section{REFERENCES}

[1] Materials Standards for PM Structural Parts. MPIF Standard 35. Edition 2018.

[2] ISKOVYCH-LOTOTSKY, R., ZELINSKA, O., IVANCHUK, Y., VESELOVSKA, N. Development of the evaluation model of technological parameters of shaping workpieces from powder materials. Eastern-European Journal of Enterprise Technologies. 2017, vol. 85, no. 1/1, pp. 9-17.

[3] DONALD, O. THOMPSON, DALE E. CHIMENTI. Review of Progress in Quantitative Nondestructive Evaluation. Springer Science \& Business Media. 1997, vol. 16, pp. 2013-2237. ISBN: 978-1-4613-7725-2,

[4] ZENGER, D.C., CAI, H., MCNEILL, J., LUDWIG, R. Classification strategy to identify and classify common cracks in green - state powered metallurgy compacts. In Review of Progress in Quantitative Nondestructive Evaluation. 1997, vol. 16, pp. 1443-1450.

[5] Handbook for sintered components, Design and Mechanical Properties. North American Hoganas, Copyright Hoganas AB, 2004. 
[6] KULKARNI HARSHAL, DADHADE, VIKRAM V. Green machining of powder metallurgy-steels (PMS). An overview. Journal of Manufacturing Processes. 2019, vol. 44, pp. 1-18.

[7] Metal Powder Industries Federation. Standard Test Methods for Metal Powders and Powder Metallurgy Products, 2019 edition

[8] An American National Standard, Standard Test Methods for Rockwell Hardness and Rockwell Superficial Hardness of Metallic Materials, revised in June 2004

[9] BOCCHINI, F.F. The influences of porosity on the characteristic of sintered materials. SAE Transactions. 1986, vol. 95, section 1, pp. 790-805. 